\title{
An Assessment of Adolescent Pregnancy and Social Risk Factors: Evidence from Agencies and Organizations in the Juvenile Justice System
}

\author{
Adrienne N. Moore \\ Department of Criminal Justice, Wiley College University, Texas, US \\ Gbolahan Solomon Osho \\ Department of Management and Marketing, Prairie A\&M University, Texas, US \\ Tel: 1-936-261-9280Ｅ-mail: gsosho@pvamu.edu
}

Received: November 10, 2016

Accepted: July 28, 2017 Published: August 21, 2017

doi:10.5296/ijsw.v4i2.10331

URL: http://doi.org/10.5296/ijsw.v4i2.10331

\begin{abstract}
In the past, it was common for young, single women who became pregnant to get married or give up their children for adoption. During the last half century, however, young women have increasingly more likely to keep their children and to be single parents; the proportion of non-marital teenage births has risen from $13 \%$ in the 1950 s to $79 \%$ in 2000 . The research seeks to describe the different organizations that are affected by teenage mothers and attempts to address teenage pregnancy and its implications for organizations/agencies such as: The Board of Education, Legislation, and Juvenile Justice System. Each one of these agencies is different entities with different functions but is detrimental in the development of teenage mothers and their journey from adolescence to adulthood. This study also aims to contribute to the body of knowledge the need for innovated programs to address the needs of these young mothers and future studies that focus on issues that arouse due to this phenomenon.
\end{abstract}

Keywords: Teenage mothers, Academic outcomes, Dropout, Promotion, Mentor, Alternative school, Traditional school 


\section{Introduction}

While adolescent parenthood is not a new issue in the United States, the nature and context of teenage parenthood has changed. In the past, it was common for young, single women who became pregnant to get married or give up their children for adoption. During the last half century, however, young women have increasingly more likely to keep their children and to be single parents; the proportion of non-marital teenage births has risen from $13 \%$ in the 1950 s to $79 \%$ in 2000" (Getsdottir, 2004). Teenage pregnancy is an issue that needs to be addressed because of future outcomes from the act. Teenage pregnancy is a phenomenon of importance because eleven percent of all U.S. child births are to teenage mothers, the U.S. has the largest teen pregnancy rate amongst all industrialized nations, two-third of teenage mothers who give birth will not complete high school and 1.5 percent of them will earn their college degree. Teenage pregnancy also cost the nation's tax payers $\$ 9.1$ billion each year, with eighty percent of the unmarried teen mothers being on welfare (Witmer, 2009). The reports show that between 2005 and 2006, the birth rate for teenagers 15-19 years rose 3 percent, from 40.5 live births per 1,000 females aged 15-19 years in 2005 to 41.9 births per 1,000 in 2006 . This follows a 14 year downward trend in which the recent peak of 62.8 births rate fell by 34 percent from its recent peak of 61.8 births per 1,000 in 1991 . The birth rate for youngest teens aged 10-14 declined from 0.7 to 0.6 per 1,000, and the number of births to this age group fell 5 percent to 6,405 . The birth rate for older teen's age 18-19 is 73 births per 1,000 populations---more than three times higher than the rate for teens age 15-17 (22 per 1,000). Between 2005 and 2006, the birth rate rose 3 percent for teens aged 15-17 and 4 percent for teens aged 18-19. (National Center for Health Statics, 2010)

In understanding the issue of teen pregnancy there should also be an understanding of what is considered delinquency and the how it differs from criminal behavior. Delinquency is deviant or mischievous behavior that researchers contribute this behavior to family upbringing, school, peer groups and environment, whereas, adult criminality differs because as adults criminal behavior contributes to lack of or ignoring of moral reasoning. In addition to the types of crimes that juveniles commit (i.e. running away, shoplifting, fighting) opposed to crimes that adults would commit (Adams, 2004). Many teenage mothers are labeled delinquent by committing truancy, running away and the act of out of wedlock pregnancy. "Girls are less likely than their male counterparts to engage in offenses, which include running away, underage drinking, truancy, and curfew violations, continue to be key factor in female delinquency" (Chesney-Lind et al., 2008).

This research will attempt to provide a foundation of how teen pregnancy is a social issue that effects' the nation on many social levels which then effect different institutionalized organizations such as: detention centers, education, health and legislation. The term teen pregnancy and adolescent pregnancy will be used interchangeable, as well as the term females, girls, offenders, teenage mothers all referring to teen mothers. This research will contribute to the working body of knowledge by offer a historical perspective on the behavior of female juvenile delinquents and adolescent pregnancy and the agencies that are affected by this phenomenon. This study will also attempt to describe how adolescent sexual behavior is are considered delinquency or deviance, which is then labeled as a status crime, a crime of being rather than a crime of doing (Webster, 2010). Teenage pregnancy is considered a status 
crime due to child birth out of wedlock, a crime of being rather than doing. In many states it is illegal for minors to engage in sex is consenting or non-consenting. "The view that adolescent pregnancy is an enormous social burden in the United States may be due to the number of teenage mothers. Teenage mothers younger than age 18 are likely to be unmarried, likely to have not completed high school and likely to have a child who live in poverty. Moreover, adolescent pregnancy is linked to other risk behaviors such as drug and alcohol use, early initiation of sexual activity and other delinquent behavior" (Rumeli, 2010).

It also interferes with adolescent transition into adulthood and becoming productive citizens, "Pregnancy itself was treated with contempt because it jeopardized the ideal purpose of adolescence, which emphasized preparing for adult roles" (Buffkin \& Luttrell, 2002). Banik (2004) elaborates on teenage pregnancy and the social issue that "the traditional negative view of teenage mothers, in which they are deemed as 'problems to be managed,' is contrasted with the perspective that these mothers are resources to be developed", she then goes further and states that, "Given the behaviors that covary with teenage pregnancy, it is not surprising that adolescents engaging in risk behaviors, such as teenage mothers, have traditionally been viewed through the lens of the deficit model, however, this is not the only approach to helping these teenagers find healthier and more successful paths to better lives.

Moreover, to examine teenage pregnancy historically in America, it is believed to be as a result in the shift in the human development of adolescence as well as the economic shift from agrarian to industrial. In early America men and women married young to avoid premarital sex and adolescent pregnancies because it was believed to be inevitable. It was common practice for the Puritans to engage in premarital sex between consenting individuals no matter the age. If there was a pregnancy then there would be an early wedding to prevent a baby out of wedlock. But, when there was a shift from agrarian to industrialization many families were no longer reliant on every family member's labor for economic stability. With industrialization growing the nation's economy, there was adaption of child labor laws preventing inhuman treatment of adolescents. This then led to the labor laws for children, replacing them with immigrants. The shift in working habits of children left them idle, the government then implicated regulations for education that would promote and encourage moral and social skills that would help to develop children into productive citizens. For decades teenage pregnancy has always created a moral panic in the early $20^{\text {th }}$ century more girls were seen in juvenile courts charged with immorality and waywardness and institutionalized until marriageable age (Buffkin \& Luttrell, 2010).

\section{Organizations/Agencies}

There are many factors that contribute to teen pregnancy. In 2006 the United States teenage pregnancy rate, ages 15 to 19 years old, rose by 3 percent 41.9 since 1991( Hamilton, Martin, $\&$ Ventura, 2007). Research to date show that teenage pregnancy effect many agencies within the United States government, an agency of focus is The Board of Education, with education affecting their future success. Studies show that academic outcomes of many teenage mothers who fall behind have a tendency of dropping out. When becoming a parent there are many responsibilities that parents experience and the lack of maturity and guidance can lead to a downward spiral if there is no proper guidance (Miranne \& Young, 2002). There are many factors that constitute for young mothers that tend to lag behind scholastically, the lack of 
support that is offered to them from family, lack of knowledge of programs that are available to them, and untreated postpartum depression that many mother experience after giving birth (Barnet et al., 2008).

In the study conducted by Barnet et al. research found that "adolescent pregnancy is associated with increased school dropout rates and decreased educational achievement. Almost half of childbearing mothers fail to complete their high school education preexisting school failure and disengagement leading to high-risk behaviors may explain the educational deficits of childbearing adolescents" (2004, p. 262). While conducting multistate study in Ohio on female juvenile inmates Sherman found that the inmates felt that there was a little placement for girls with babies and education on parenting, (Chesney-Lind et al., 2008, p. 168). Not only is education affected by adolescent pregnancy but teen pregnancy also affects legislation. Former President George W. Bush's plan required that more families work more hours on order to receive welfare assistance. Under this proposal families would be required to engage in a work activity 40 hours per week - a one third increase from the current 30 hour requirement (20 hours for a single parent with young children). In addition the Bush administration also required states to put 70 percent of their caseload to work or suffer financial consequences. Currently states have one third of their caseloads in work. This bill affect teen mothers in that it required them to maintain work or attend school or training in order to receive benefits, "from welfare to work" reform (Sugalia, 2010).

Moreover, "for decades, policymakers have been concerned about teenage childbearing and the perceived link to welfare recipients. The belief that access to welfare benefits encouraged young woman to have children out of wedlock was reflected in provisions of the Personal Responsibility and Work Opportunity Reconciliation Act of 1996 (PRWORA) that were designed to reduce teen and non-martial births. Mandated policy initiatives included restrictions of benefits to unwed teen parents under age 18 who were not residing with a parent/guardian and were not attending school, a federally funded abstinence education program (focusing on abstinence from sex not birth control or family planning), and bonuses to the state the ranked the highest in reducing non-martial births while also decreasing abortion" (Miranne \& Young, 2002). The PRWORA of 1996, National Campaign to Prevent Teen Pregnancy found in 1995 to reduce pregnancy rates between 1996 and 2005. Through policies and organizations the federal government hoped to reduce teen pregnancy and offer assistance to the community leaders with addressing and developing programs that prevent and reduce the number of non-martial child births. This is where the abstinence programs were developed. They offered more funding to the communities that actually achieved this goal, yet it did not fund organizations that offered information on preventive care and other health services and they were found to be ineffective (Suglia, 2010).

The final focal organization in this study is the juvenile justice system. As stated prior teenage mothers are considered as being at risk because of their circumstances as young mothers and are forced into the juvenile justice system. "Although media attention to female juvenile crime has increased over the past decade-mostly around sensationalized issues such as 'girl and gangs'-the research on issues, policy, and programs for at-risk adolescent females has, for the most part, been overlooked. Girls and young women confront additional problems unique to their gender, such as sexual abuse and assault, teenage pregnancy, single 
parenthood, and disparity in education, vocational, and employment opportunities" (Bloom, 2010). Bloom then describes the lack of education, unskilled, poor and disproportionately women of color are trapped in the system. She attributes at-risk adolescent females as having the following characteristics:

1) Age 13 to 18 years.

2) History of victimization especially physical, sexual, and emotional abuse.

3) Academic failure, truancy, and dropout.

4) Repeated status offenses, especially running away.

5) Unstable family life, including family involvement in the criminal justice system, lack of connectedness, and social isolation.

6) History of unhealthy dependent relationships, especially with older males.

7) Mental health issues, including history of substance abuse.

8) Overrepresentation.

In Roberts (2010) research on teen pregnancy and delinquency finds that behavior factors are also associated with teenage pregnancy. She also discovers that dating early, same-sex relationships, drug usage, cigarette or marijuana smoking, and alcohol are all associated. They are less involved with family and are more likely to have friendship and bonds with other teen parents, which is another issue that should be addressed in another study of social bonds and their effects on teenage mothers (2010). As aforementioned, delinquency is not a criminal act but behavior issues. Due to behavior issues that are commonly associated with teenage mothers, "conclusions can be drawn regarding the risk factors associated with teenage pregnancy, the link between teenage pregnancy and delinquency, and the characteristics of those most likely to become teenage parents"(Buffkin \& Luttrell, 2010). Chesney-Lind et al. (2008) found that many of the teen mothers in the detention centers felt that they did not receive the essential tools that are needed to be better parents and productive citizens upon being released.

\section{Theoretical Perspective}

The theoretical perspective used in this research is the feminist perspective and positive youth perspective theory. The feminist perspective theory is significant to this research because it describes how social views impact females. In here description of the feminist perspective, Gwynn (1993) attributes, "While there are many streams of feminist beliefs, feminism is generally understood to be a world view encompassing assumptions and beliefs about the origins and consequences of gendered social organizations, as well as strategic directions and actions for social change. Feminism itself is not a single theory and has expanded into an extensive set of perspectives and agendas defining the problems associated with gender inequality and steps for its eradication. What these perspectives do have in common is a concern to identify and represent the interests of women, interests who are judged to be insufficiently represented in mainstream" (p. 99). Gwynn links social issues, organizations and social change as being components in the feminist perspective theory these are common issues that are found in the struggle of teenage motherhood. Teenage pregnancy is synonymous to feminism being that the parent who is social viewed as the primary care giver is the mother and the mother is a woman. 
Positive youth development perspective is a theory based on developmental context. This is the belief that an individual's reaction to theory own personal experiences creates their character and these are beliefs that are embedded in them and causes a systematic change. This is associated with adolescent parenting because the teen mothers' lives change drastically after childbirth. Positive youth development perspective vision is to offer hope, this theory is important in the development of teen mothers in that they need assistance in theory maturing as adults and young parents, with hope that they develop and grow into productive citizens within society (Banik, 2010).

\section{Prior Research}

In the essay Teen mothers and welfare reform: challenging the boundaries of risk, "policies are partially in response to statistics reporting that nearly half of all teen mothers apply for welfare benefits within five years after becoming a parent. Prior to enactment of the 1996 legislation, the majority of young mothers who went on welfare stayed on the rolls for at least two years with many reaming much longer" (Miranne \& Young, 2002). Not only does teenage mothers presence affect legislation and welfare reform, but on the front end the lack of education leads to continuous welfare recipients, this is where the board of education becomes an affected agency because of truancy from absenteeism and truancy trickles down into the juvenile justice system, where there is a lack of case studies and support groups that offer the essential tools for growth into productivity as adults (Liefeld \& Solomon, 1998; Miranne \& Young, 2000; Chesney-Lind et al., 2008).

Hence, teenage mothers are faced with more responsibilities such as doctor's appointments and other necessities that could contribute to excessive absenteeism. This study will examine how teen pregnancy and motherhood affects academic outcomes. Studies show that, "more than two-thirds of all teenagers who have a baby will not graduate from high school...only 1.5 percent of teen mothers have a college degree by age of 30,"(Witmer, 2006). Information will be gathered in search of factors that are predictive of teenage mother's persistence in education or the lack thereof. This study will utilize secondary data gathered from 25 teenage mothers, age 14 to 18 years old and their academic outcomes. The study will also offer possible policies that will provide assistance to teenage mothers and encourage academic achievement.

Teenage pregnancy is at a rise in the United States and teen pregnancy contributes to academic shortcomings. Research found that with teenage pregnancies only half of these mothers actually graduate from high school (Arroyo et al., 2004, p. 262). This contributes to possible long term factors such as: poverty, social disadvantages, parenting issues, and health issues. Due to poor academic outcomes, the research in this study provides information showing the relationship between academic outcomes and the dropout rate of teenage mothers. The dropout rate is also related to social outcomes because without an education lack of possible employment opportunities. Many of these mothers are considered social deviants because of their lack of knowledge and incompletion of school and the behavior that they adapt in order to survive. Research found that many teenage girls who become pregnant by the age of 14 become pregnant for men ages 20-40 years of age, that in certain situations expose them to additional dangers. This study suggests that the lack of support from family relates to this (Chesney-Lind et al., 2008, p.165). 
The many social problems that affect adolescent's teen pregnancy are viewed as being very problematic and it is also associated with school failure. In a study conducted by Allen, Philliber, Herrling, and Kuperminc (1997) an experimental evaluation was conducted to test the problem behaviors of teens and enhancing social development of high school students. The experiment was randomly assigned to either Teen Outreach control or a control group with 25 national sites. The researchers sought out student's socio-demographic characteristics and the differences of each group. The results from this study showed that the value of teen outreach should address broad developmental tasks of teens rather than individual problem behavior.

Solomon and Pierce (1998) research of teen mothers, their academic outcomes, and the effectiveness of family support found that these factors influenced the dropout rates of teenage mothers. The research in this study was conducted in an urban setting with first-time teenage mothers. The research was developed to reduce repeated pregnancy and school dropout rates. The mothers were assigned to either intervention or control groups. Assessments of these mothers were taken shortly after child birth; follow up home visits were conducted in 24 months. Results suggest that there is a significant difference shared between intervention and control. Intervention programming assists teen mothers subsequently more than the controlled sample testing.

Harris and Franklin (2007) conducted a quasi-experiment at an alternative school with nineteen participants. The data collected in the experiment were school records that measured the participant's school attendance and grade point averages. The study found that the girls that participated in the Taking Charge group, a group design is to assist with the teen parents in their academics and encourage them to attend school, had better chances of remaining in school while participating in the program than girls who did not participate. This article relates to the study because it describes the need for programs within the school system for teen mothers that will allow them to continue in their studies and offering them mentorship that will assist them in their completion of high school.

Not only are family relationships and social bonds are connected to adolescent pregnancy, but studies show a relationship to drug usage. McCluskey, Krohn, Lizotte, and Rodriguez (2002) suggest that there is a grave difference in the how Hispanic culture view education and pregnancy may be the cause of why Hispanic teen mothers lead in the dropout rate. With language barriers and poor schools the education system is suggested by the authors as not being importance in the economic and educational growth of the mothers. This is important to the study because it describes how the Hispanic culture possible view education, while offering different variable that can possible contribute to this socieconomics, cultures beliefs and understanding of education, and poor learning institutions.

Harner (2004) evaluates outcomes of teenage mothers with adult partners and domestic violence and how their relationships compare to other teenagers partnered with male peers. The experiment was administered to English -speaking teenagers who recently gave birth in an urban teaching hospital with a study of eighty-six teenagers. The design is non-experimental and utilizing descriptive comparative design. The instrument used was The Abuse Assessment Screen and the Danger Assessment Scale. The method used for this study was semi-structured interviews lasting 30 minutes to two hours in length. The imbalance in 


\section{Macrothink}

International Journal of Social Work

ISSN 2332-7278

2017, Vol. 4, No. 2

the relationships of teenagers and adult partners in these situations result in lack of education and other economic growth of the teenage mothers because of fear. This research relates to the hypothesis because of the relationships that are shared with the adult men affecting the teen mothers' growth educational and economically. These imbalances of power relationships may include economic and educational status and other physicalities. The result from this study is that teenagers with adult partners are less likely to report experiencing domestic violence and trauma related care during their pregnancy than teenagers with peer-aged partners.

Related study that can be connected to fears commonly found amongst teen mothers, Barnet, Liu, and Devoe (2008) examine the depressive symptoms and risk factors of pregnant adolescents. The study used secondary analysis from longitudinal risk reduction intervention. It used five community based sites in Baltimore, Maryland. The participants were composed of 269 consenting teens predominantly African-American in low income homes. This relates to the hypothesis study because untreated depression is associated with illnesses that potentially affect teenage mother's dropout rates due to excessive absentees. The result from this study showed that in two years after pregnancy mothers suffered from postpartum depression. Mollborn and Morningstar (2009) examine psychological distress of teenage mothers in their longitudinal study. The study found that teenage mothers had higher distress levels than that of non-childbearing peers. This study also concluded that teen parents that were poor distress levels increased frequently. This is relevant to this study because the distress levels could be a possible variable of why many young woman are not attend school not knowing how to deal with the feelings and the emotions that they are enduring and how it affects their social life.

Pogarsky, Lizotte, and Thornberry (2003) associate delinquency to anti-social behavior that is passed down to children. The study utilized data taken from the Rochester Youth Development Study using a longitudinal study of adolescent development. The "early first-birth effect" examined how children born to teen mothers tend to be delinquent because of the lack of education and economic stability. This research relates to the hypothesis of this study because the lack of family structure is described as one of the variables that contribute to the teenage pregnancy, the lack of the support within the home causes economic constraints that contributes to the teen mothers academic outcomes while in school.

Hence, Arroyo, Barnet, Devoe, and Duggan (2004) evaluate adolescent pregnancy and how it is associated with the increase in dropout rates and academic outcome. The method used in this study was school rosters from an alternative school that identified adolescents 18 and under who gave birth to children between July 1, 1995 and August 1, 1997 in Baltimore, MD. This study evaluated the use of school -based prenatal care on dropout and promotion or graduation rates. The results identified 431 African-American low income adolescents who attended the alternative school and their performances that displayed significant absenteeism and poor performance in school during the pregnancy. Girls who received prenatal care were absent 12 fewer days compared to those who did not. This study explains the need for support groups and proper guidance will assist in alleviating some of the issues of truancy among teen mothers. As a result to delinquency and behavior issues, Chesney-Lind, Morash and Stevens (2008) explained the connection between girls in the juvenile justice system and the 
essential tools that are needed to better the programs that are currently being utilized. This study collected data from several female juvenile delinquent centers in the United States. This research shares relationship with the hypothesis study because the juvenile delinquents who are teen mothers that are incarcerated and the wants and needs are expressed in this study for assistance with education, parenting and career building programs. The result from this research is that the young women are in need of programs that assist in future growth and empowerment.

Hope, Wilder, and Watt (2003) write that there was an application of criminological theories of social control that should be explored among adolescent pregnancy. In this study it was discovered that teenage pregnancy is a contributing factor in the U.S. deficit. With two-thirds of teenage mothers actually completing high school and remaining on welfare unable to provide for their children. This study is relevant because the lack of academic outcomes leads to social and economic issues. Furthermore, Brace, Hall, Hunt (2008) argue that teen pregnancy is a public health concern that cost the United States $\$ 9.1$ billion annually. The study purpose is to offer intervention through research performed at the Circle of Care intervention program and teen pregnancy prevention programs in Troup County, Georgia. The results from this study showed an increase in completion of school, higher rates in school enrollment, health benefits, no repeat pregnancies, child abuse and project cost dropped. The relevance in this is study is through program implementation and awareness of resources within the community the teen mothers can be productive within the community also offer the assumption that community involvement is beneficial in their growth.

\section{Findings}

The table presented below examines whether multidimensional treatment foster care services are relative to intervention services and do they decrease pregnancy rates among juvenile justice girls who are mandated to out-of- home care: Baseline characteristics of participants are reported in Table 1. Within each trial, GC and MTFC participants did not differ on any baseline measure. The participants did not differ between trials on any baseline measure, except for sexual activity (Trial $1=90.1 \%$; Trial $2=77.4 \%$ ), $\chi^{2}(1, N=165)=4.89, p<.05$, for which measurement differed slightly by trial.

Table 1. Values on study covariates and outcomes by group and trial

\begin{tabular}{lllll}
\hline & Trial 1 & \multicolumn{3}{l}{ Trial 2 } \\
\hline Covariates/Outcomes & GC & MTFC & GC & MTFC \\
\hline Baseline $(n)$ & 44 & 37 & 41 & 44 \\
Age in years, M (SD) & $15.1(1.1)$ & $15.4(1.1)$ & $15.4(1.3)$ & $15.3(1.1)$ \\
Criminal referrals, M (SD) & $11.7(8.1)$ & $12.4(9.9)$ & $12.2(7.6)$ & $11.4(6.9)$ \\
Sexual activity ${ }^{\text {a }}(\%)$ & 90.9 & 89.2 & 82.9 & 70.5 \\
Pregnancy history (\%) & 29.5 & 27.0 & 22.0 & 22.7 \\
6 months $(n)$ & & & 32 & 41
\end{tabular}


Pregnancy since baseline (\%)

9.4

2.4

12 months $(n)$

Pregnancy since baseline (\%)

18 months $(n)$

Pregnancy since baseline (\%)

24 months $(n)$

Pregnancy since baseline (\%) 42

41

21.3

33

15.2

39

17.9

44

29.1

39

44

23.1

11.4

39

38.5
44

22.7

Note: $n$ s and pregnancy rates are based on cumulative participation at follow-up assessment, and they do not correspond to participation and pregnancy rates at individual time points, $G C=$ group care; $M F T C=$ Multidimensional Treatment Foster Care.

${ }^{a}$ Sexual contact in past month (Trial 1) or 6 months (Trial 2).

\section{Values on Study Covariates and Outcomes by Group and Trial}

Follow-up pregnancy rates are reported in Table 1. Univariate logistic regressions supported that fewer MTFC girls reported a pregnancy (26.9\%) during follow-up than did GC girls $(46.9 \% ; n=159$, Wald $=8.34, p=.004$, odds ratio $[\mathrm{OR}]=0.42,95 \%$ confidence interval $(\mathrm{CI})$ $=0.23-0.75)$. Groups appeared to differ by $6-12$ months post baseline and to continue to diverge; the study design, however, precluded testing these patterns formally. Baseline number of criminal referrals $(\mathrm{OR}=1.05,95 \% \mathrm{CI}=1.01-1.08, p=.010, n=159)$, sexual activity $(\mathrm{OR}=3.70,95 \% \mathrm{CI}=1.17-11.67, p=.025, n=158)$, and history of a prior pregnancy $(\mathrm{OR}=3.12,95 \% \mathrm{CI}=1.47-6.64, p=.003, n=158)$ each predicted follow-up pregnancy, whereas missingness, age, trial, and the Group $\times$ Trial interaction did not. The final model controlled for significant covariates (see Table 2). The significant group effect supported that MTFC decreased the probability of pregnancy after baseline relative to GC. Expressed inversely, the odds for becoming pregnant during the follow-up period were 2.44 times larger for GC than for MTFC girls. Baseline pregnancy and criminal referral histories remained independently associated with increased likelihood of post baseline pregnancy.

Table 2. Results of final logistics regression predicting pregnancy in the 24 months following baseline

\begin{tabular}{lllll}
\hline Predictor & $B$ & $S E(B)$ & OR & $95 \%$ CI \\
\hline Baseline criminal referrals & 0.05 & 0.02 & $1.05^{* *}$ & $1.00-1.10$ \\
Baseline sexual activity & 1.04 & 0.61 & $2.83^{*}$ & $0.86-9.26$ \\
Baseline pregnancy history & 1.22 & 0.41 & $3.38^{* *}$ & $1.50-7.60$ \\
Group (GC or MTFC) & -0.89 & 0.31 & $0.41^{* *}$ & $0.23-0.75$ \\
\hline
\end{tabular}

Note: Model $R^{2}(n=158)=.209, p=.004$. Baseline pregnancy history, sexual activity, and the pregnancy outcome were coded as follows: 0 (negative) or 1 (positive). Group was coded 
as follows: 0 (group care $[G C]$ or 1 (Multidimensional Treatment Foster Care [MTFC]). OR $=$ odds ratio; $\mathrm{CI}=$ confidence interval. ${ }^{*} p<.10 .{ }^{*} * p<.01$

One exploratory analysis was aimed at elucidating mechanisms of effect. The interaction between intervention group and baseline criminal referrals was added to the primary model and was found to be significant: $B=-0.132, S E(B)=0.035, p<.001$. Post hoc probing, controlling for final model covariates, indicated that baseline criminal referrals predicted follow-up pregnancy among girls assigned to $\mathrm{GC}(\mathrm{OR}=1.14,95 \% \mathrm{CI}=1.08-1.21, p<.001$, $n=80)$ but not among those in MTFC (OR $=1.00,95 \% \mathrm{CI}=0.96-1.04, p=.86, n=78)$. Source: Kerr \& Leve, 2009.

\section{Policy Implications}

This study found that there is a need for more studies to be conducted on teenage mothers with the juvenile justice system and by the Board of education. Though there are policies adapted to assist teenage mothers there is a need for programs that specialize in assisting these parents in economic growth for future support for their children. In researching this topic it was found that there is a link between the upbringing of teen mothers and their families, therefore there is a need for support groups that will assist with possible issues that arouse within these households being that legislation force the mothers to remain in homes with their parents in order to receive financial assistance.

In regards to policy implications, results from this study and previous findings there is a need for counseling for these young mothers. There is a need for program implications within schools that will offer parenting classes and support groups that will influence the mothers to remain in school and assist them with needed medical needs that could possible hinder their educational growth. In the research show that many mothers are not continuing with their education because of medical needs of their children and at times for themselves. Implication of programs that cater to the health needs of the mothers and their children while attending school may assist in preventive care that could later contribute to their truancy because of health issues.

\section{Program Implications}

Conclusively there is a need for programs that cater to health care needs for both the mothers and their children, but there is a need to implement more programs for teen mothers that offers mentorship, guidance and parenting skills. Mentorship programs within the school systems could be implemented after reviewing the findings of where the teen mothers reside. The lack of leadership within the home allows the assumption to be made that single parent homes could possibly have less parental involvement because of one person supporting the family. It could also be assumed that there is less time to be involved in the teenage mother's educational needs. There needs to be a balance of school, parenting skills, and family structure that could be taught through mentor and leadership programs for the young mothers. All of this can be achieved through possible implementation of programs within the school systems, afterschool programs and community service agencies. These programs should not conflict with the young mothers' daily academic learning. 
Programs that offer case management that ensure the mothers remain in school or re-enter school after delivering their baby will assist in the completion of school and build upon future career goals. The case manager will offer the appropriate services to each teen mother for each mothers' own personal individual needs. There will be assessments given to determine the specific needs for each individual family. The mothers will also need parenting classes to assist them in how to manage their time and balance parenting and school. Family planning services will also be implemented for preventive care and healthcare awareness.

Therefore there is need for mentorship and role models within the community. It can be assumed from the findings that without support there is a threat of possible truancy amongst teenage mothers because the lack of knowledge on what resources are available to them. With better measures of policy instruments, it may be possible to obtain direct evidence of the effects of these interventions on teenage mothers' educational attainment. There should be future research conducted on teenage pregnancy and programs implemented into their daily curriculum as well as research on teenage mothers within juvenile detention centers.

\section{References}

Allen, J., Herrling, S., Kuperminc, G., \& Philliber, S. (1997). Preventing teen pregnancy and academic failure-experimental evaluation of a developmentally based Approach. Child Development, 64, 729-742. https://doi.org/10.2307/1132122

Arroyo, C., Barnet, B., Devoe, M., \& Duggan, A. (2004). Reduced school dropout rates among adolescent mothers receiving school-based prenatal care. Arch Pediatric Adolescent Medicine, 158, 262-268. https://doi.org/10.1001/archpedi.158.3.262

Banik, R. (2010). Adolescent mothers. Encyclopedia of applied development science. Sage.

Baumgardner \& Black. (2010). Parenting in adolescence. Encyclopedia of applied developmental science. Sage.

Barnet, B., Liu, J., \& Devoe, M. (2008). Double Jeopardy: depressive symptoms and rapid subsequent pregnancy in adolescent mothers. Arch Pediatric Adolescent Medicine, 162, 246-252. https://doi.org/10.1001/archpediatrics.2007.60

Bloom, B. (2010). Female Delinquency, II. Current Status. Encyclopedia of juvenile justice. Sage.

Brace, A., Hall, M., \& Hunt, B (2008). Social, economic and health costs if unintended teen pregnancy: The circle of care intervention program in Troup County, Georgia. Journal of the Georgia Public Health Association, 1, 33-46.

Bufkin \& Luttrell. (2010). Pregnancy, Teen. Encyclopedia of juvenile justice. Sage

Bye, L., Shepard, M., Patridge, J., \& Alvarez, M. (2009). School social work outcomes: Perspectives of school administrators. Children and Schools, 31, 97-108. https://doi.org/10.1093/cs/31.2.97

Chesney-Lind, M., Morash, M., \& Stevens, T. (2008). Girls' troubles, girls' delinquency, and gender responsive programming: A Review. The Australian and New Zealand Journal of Criminology, 4, 162-189. https://doi.org/10.1375/acri.41.1.162

Gestsdottir, S. Adolescent parents, programs, and policies. Encyclopedia of applied science. Sage. 
Gwynn, C. (1993). Women and crime: The failure of traditional theories and the rise of feminist criminology. Monash University Law Review, 19(1).

Harner, H. (2004). Domestic violence and trauma care in teenage pregnancy: Does paternal age make a difference? JOGNN Clinical Research, 33, 312-319. https://doi.org/10.1177/0884217504264867

Harris, M., \& Franklin, C. (2009). Helping adolescent mothers to achieve in school: An evaluation of the Taking Charge Group intervention. Children and Schools, 31, 27-34. https://doi.org/10.1093/cs/31.1.27

Harris, M., \& Franklin, C. (2007). Taking charge: A life skills group curriculum for adolescent mothers. New York: Oxford University Press. https://doi.org/10.1093/acprof:oso/9780195172942.001.0001

Hope, T., Watt, E., \& Wilder, E. (2003). The relationships among adolescent pregnancy, Pregnancy resolution, and Juvenile delinquency. The Sociological Quarterly, 44, 555-575. https://doi.org/10.1111/j.1533-8525.2003.tb00525.x

Kerr \& Leve. (2009). Pregnancy rates among juvenile justice girls in two randomized controlled trials of multidimensional treatment foster care. Journal of consulting \& clinical psychology, 7(3), 588-593.

Kirby, D. (2002). The impact of schools and school programs upon adolescent sexual behavior. The Journal of Sex Research, 39, 27-33. https://doi.org/10.1080/00224490209552116

Liefeld, C., \& Solomon, R. (1998). Effective of a family support center approach to adolescent: mothers: repeat pregnancy and school dropout rates. Family Relations, 47, 19-144.

Lizotte, A., Pogarsky, G., \& Thornberry, T. (2003). The delinquency of children born to young mothers: results from the Rochester youth development study. Criminology, 41, 1249-1285. https://doi.org/10.1111/j.1745-9125.2003.tb01019.x

Moore, R. (2005). Attendance: Are penalties more effective that rewards? Journal of Developmental Education, 29, 26-32.

Miranne, K., \& Young, A. (2000) (Eds.) Teen Mothers and welfare reform: Challenging the boundaries of risk. Lanham, MD: Rowman \& Littlefield.

McCluskey, C., Krohn, M., Lizotte, A., \& Rodriguez, M. (2002). Drug use, academic achievement, Hispanic Americans, African Americans, Whites. Journal of Drug Issues, 32, 921-944. https://doi.org/10.1177/002204260203200313

Mollborn, S., \& Morningstar, E. (2009). Investigating the relationship between teenage childbearing and psychological distress using longitudinal evidence. Journal of Health and Social Behavior, 50, 310-327. https://doi.org/10.1177/002214650905000305

Roberts, D. (2010). Teenage Pregnancy. Encyclopedia of Human Development. Sage.

Sims, K., \& Luster, T. (2009). Factors related to early subsequent pregnancies and second births among adolescent mothers in a family support program. Journal of Family Issues, 23, 1006-1031. https://doi.org/10.1177/019251302237301 


\section{Macrothink}

International Journal of Social Work

ISSN 2332-7278 2017, Vol. 4, No. 2

Schelar, E., Franzetta. K., \& Manlove, J. (2007). Repeat then childbearing: Differences across states by race and ethnicity. Child Trends Research Brief, 23, 1-7.

Suglia, S. (2010). Pregnancy of Students. Encyclopedia of educational leadership and administration. Sage.

Sullivan, M. (1993). Culture and class as determinants of out-of-wedlock childbearing and poverty during late adolescence. Journal of Research on Adolescence, 3, 295-316. https://doi.org/10.1207/s15327795jra0303_5

Terry-Humen, E., Manlove, J., \& Cottingham, S. (2006). Trends and recent estimates: Sexual activity among U.S. teens. Child Trends Research Brief, 1-8.

Witmer, D. (2009). Why should teen pregnancy concern everyone? About.com. Retrieved September 13, 2009, from http://parentingteens.about.com

\section{Copyright Disclaimer}

Copyright reserved by the author(s).

This article is an open-access article distributed under the terms and conditions of the Creative Commons Attribution license (http://creativecommons.org/licenses/by/3.0/). 